\title{
Auswirkungen des extrem heißen Sommers 2018: Ein kurzer Erfahrungsbericht aus dem Palmengarten, Stand August 2018
}

Die Bepflanzung in unseren beiden Gärten ist unser „Kapital“, das erhalten werden muss. Hierunter befinden sich viele seltene und wertvolle Pflanzen. Die anhaltende Trockenheit erfordert zunehmend die Versorgung von Großgehölzen und Bäumen, die bei kurzen Trockenheitsperioden in der Regel noch nicht zusätzlich mit Wasser versorgt werden müssen, um Trockenschäden zu vermeiden.

Wir bewässern mit Augenmaß und achten darauf, dass wir beim Gießen kein Wasser verschwenden.

Bislang gibt es keine Pläne oder Vorgaben, davon abzuweichen.

Dadurch kann der Palmengarten und der Botanische Garten durchaus als grüne Oasen in der Stadt bezeichnet werden, was nicht nur bei den
Besuchern und Besucherinnen gut ankommt, sondern auch die Innenstadt profitiert klimatisch davon.

Der Wasserverbrauch in unseren beiden Gärten liegt in diesem Jahr geschätzt bei 30-50 \% über dem Niveau vom letzten Jahr. Dies ist allerdings nur eine Schätzung, seriöse Zahlen können erst Ende des Jahres zusammengestellt werden. Die Bewässerung der Pflanzen und Anlagen stellen derzeit die Haupttätigkeiten des gärtnerischen Personals dar, vorrangig vor anderen Kulturarbeiten, die nur noch in eingeschränktem Umfang wahrgenommen werden können.

Hitzeschäden stellen wir vor allem bei Gehölzen fest, die aus kühlen und gemäßigten Regionen stammen. Auffallend sind beispielsweise vorzeitig einsetzender Laubfall bei Kastanien und

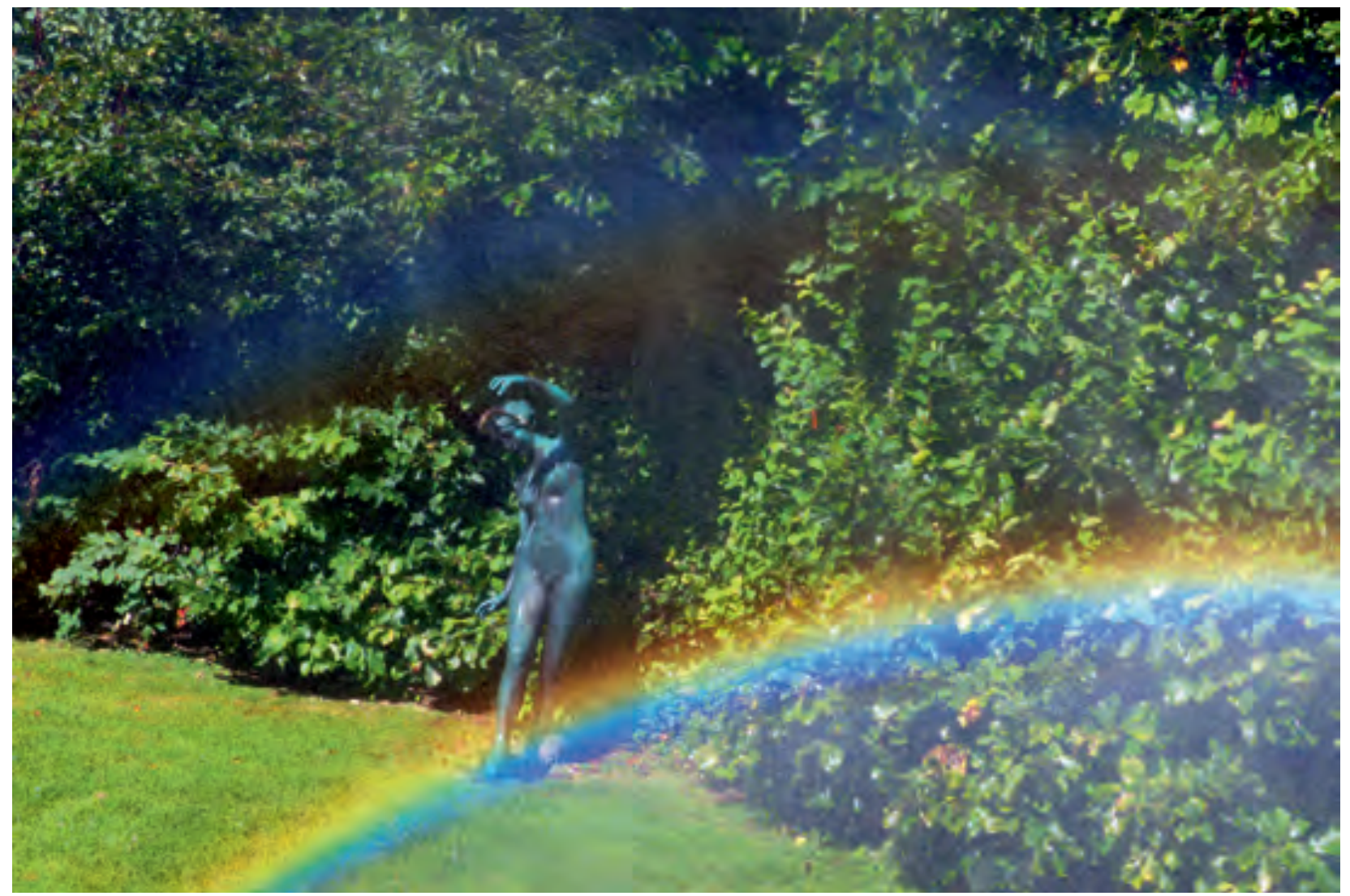

Abb. 1: Das Wässern des Gartens ist eine der Hauptaufgaben im heißen Sommer 2018. Dadurch ergeben sich gelegentlich interessante Regenbogen-Effekte. (Foto: H. STEINECKE) 
Linden, sowie Grünastabbrüche bei heimischen Eichen (Quercus robur). Solche Ereignisse sind eher typisch für Weichhölzer wie Pappeln und Weiden. Auch Rot-Buchen zeigen das, wenn sie wie hier in Frankfurt nicht auf ihnen angepassten Standorten stehen. Im Botanischen Garten gab es schon zwei Starkastabbrüche bei Eichen im grünen Zustand, also volle Belaubung. Auch sehen die Eichen insgesamt wenig vital aus. Viele Trockenschäden an Bäumen zeigen sich allerdings erst in den Folgejahren und führen zu einem erhöhten Bedarf an baumpflegerischen Maßnahmen in der Zukunft.

Kakteen hingegen schadet die Hitzeperiode nicht, denn Sonne und hohe Temperaturen gibt es auch reichlich an ihren natürlichen Standorten. Cleistocactus samaipatanus blüht gerade üppig in der Halbwüste des Tropicariums.

Für mediterrane Pflanzen wie Pinien, Olivenbäume, Zistrosen und trockenheitsliebende Pflanzen aus Steppenregionen oder die große Zahl der Palmen im Außenbereich stellt die derzeitige Witterung kein Problem dar.

Die Situation der Weiher im Palmengarten und im Botanischen Garten erscheint stabil. Es musste zurzeit noch kein Fisch-Sterben registriert werden, wie es in anderen Naturgewässern in Deutschland schon zu beobachten war. Der Sauerstoffgehalt scheint zurzeit noch nicht kritisch zu sein. Das großzügige Abfischen der Karpfen am großen Weiher im Palmengarten hat sich auch inzwischen positiv bemerkbar gemacht. Der kleine Weiher im Palmengarten hat einen regen Algenbewuchs, dies erscheint aber nicht viel mehr als in den Jahren zuvor.

Aus technischer Sicht macht die Hitze erstaunlich wenige Probleme, nur Lesegeräte für die Jahreskarten setzen ab und an aus, wenn sie überhitzt sind.

Das heiße Wetter hatte bislang weder einen positiven noch negativen Ausschlag auf die Besuchszahlen im Palmengarten (ohne Musikveranstaltungen). Im Juli 2018 lag die Zahl der Besucher und Besucherinnen bei rund 57.000. Dies

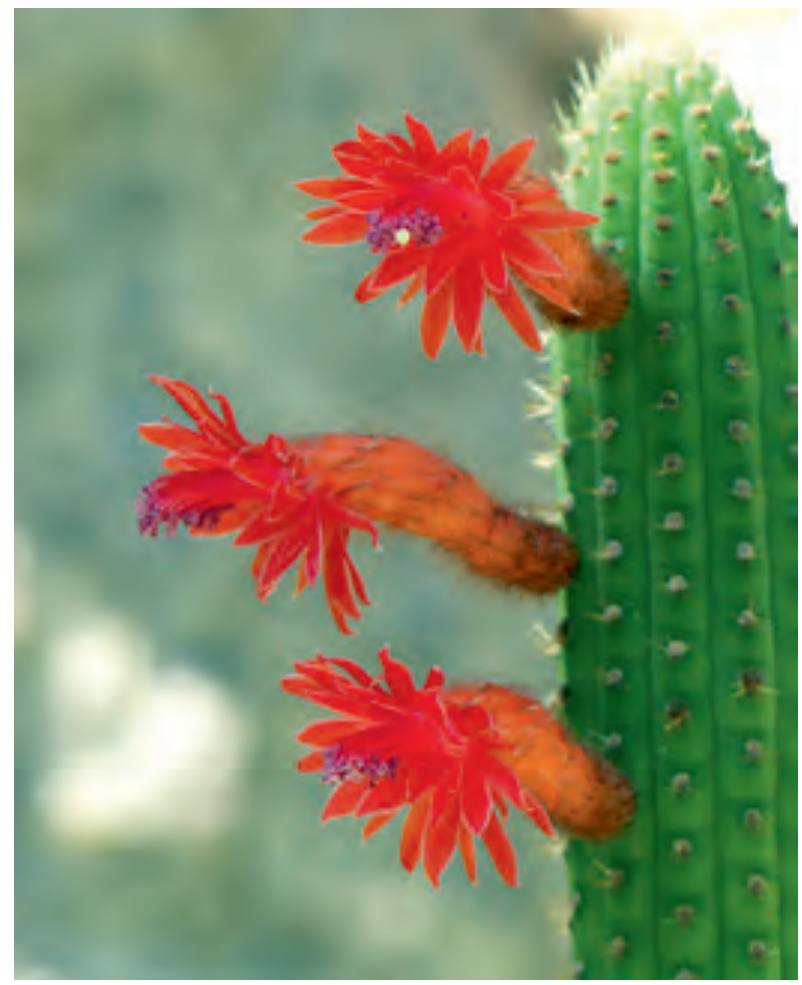

Abb. 2: Cleistocactus samaipatanus in voller Blüte.

(Foto: H. Steinecke)

entspricht den Besuchszahlen aus den Jahren zuvor. Die Einnahmen im Juli lagen knapp über denen des Vorjahres.

Wir bemerken anhand der Fragen und Kommentare zum Wasserspielplatz, dass dieser im Moment sehr gefragt ist.

Trotz der Hitze zieht die „Musik im Palmengarten " viele Konzertbesucher an, die sich über die schönen, regenfreien und lauen Sommerabende im Palmengarten freuen. Die Konzerte der Reihe "Jazz im Palmengarten" besuchten bisher konstant zwischen 600 und 750 Gäste. Dies übersteigt die Besucherzahlen der Konzerte im Vorjahr, teilweise sogar um das Drei- bis Fünffache. Auch die Konzerte der Reihe „Summer in the City“, ausgerichtet vom Künstlerhaus Mousonturm, erfreuen sich großer Beliebtheit. Zwei der bisherigen drei Konzerte waren mit über 1100 Gästen ausverkauft. Die weiteren Formate, wie die Promenadenkonzerte am Sonntag, als auch die Vorstellungen der Kammeroper Frankfurt, verzeichnen ebenfalls gute Besucherzahlen, an denen kein Einbruch durch die Hitze erkennbar ist. 